\title{
Diáspora Negra: Desigualdades de Gênero e Raça no Brasil
}

\author{
Black Diaspora: Gender and Race Inequality in Brazil
}

\author{
Maria Inácia D'Avila Neto \\ Universidade Federal do Rio de Janeiro \\ inadavila@gmail.com

\section{Claudio Cavas} \\ Universidade Federal do Rio de Janeiro \\ claudiocavas@ig.com.br
}

\section{Resumo}

A proposta do presente trabalho é discutir a diáspora negra no Brasil e sua relação com as desigualdades de gênero e raça, baseada nos estudos culturais, póscoloniais e feministas. O artigo apresenta os principais conceitos do quadro teórico adotado, descrevendo-os como um projeto político e epistemológico para a busca de reconhecimento por parte das mulheres brasileiras afro-descendentes.

Palavras - Chave: Diáspora Negra; Gênero; Raça; Reconhecimento.

\begin{abstract}
The purpose of this work is to discuss the black diaspora in Brazil, and its relation with gender and race inequality based on cultural, post-colonial and feminist studies. The article presents the main concepts of the adopted theoretical picture describing them as a political and epistemological project to the search of recognition by AfroBrazilian descendant women.
\end{abstract}

Keywords: black diaspora; gender; race; recognition. 


\section{Diáspora Negra: Desigualdades de Gênero e Raça no Brasil}

Durante a colonização, aqui conviviam, brancos, índios, negros e seus descendentes miscigenados, observados por Darcy Ribeiro, no que ele chamava o processo de fazimento da cultura brasileira (RIBEIRO, 1995). Apesar da diversidade, não cabia se falar em reconhecimento das diferenças; a 'ordem do mundo' colonial obedecia a um critério eurocêntrico supremacia do colonizador europeu e branco sobre o índio, o negro, os mestiços e androcêntrico, supremacia do masculino sobre as mulheres - gerando opressões que se traduziam em racismo, discriminação sexual e social. O negro foi importado da África para o trabalho escravo no Brasil Colonial, durante mais de trezentos anos:

Calculo que o Brasil, no seu fazimento, gastou cerca de 12 milhões de negros, desgastados como a principal força de trabalho de tudo o que se produziu aqui (...). Ao fim do período colonial, constituía uma das maiores massas negras do mundo moderno (RIBEIRO, 1995, p. 220).

A ausência de políticas de inserção social e econômica para afro-descendentes, no período pósabolição da escravatura, veio agravar as enormes assimetrias, que perduram até os dias de hoje e que marcam ainda mais as mulheres. Desde o Brasil Colônia, as mulheres negras eram utilizadas como mão de obra escrava servindo de mucamas e amas de leite, prestando favores sexuais aos seus senhores e, ainda hoje, perpetuadas em ofícios como cozinheiras, arrumadeiras, faxineiras. Se a abolição da escravatura lhes concedeu a liberdade, dessa liberdade pouco puderam usufruir, uma vez que ser mulher, negra e pobre, já era um estigma que significava: inferioridade, ignorância, subalternidade e ausência de direitos mínimos que assegurasse sua cidadania.

Segundo os dados da Pesquisa Nacional por Amostra de Domicílio (PNAD) 2003 do IBGE, as mulheres representam $42,7 \%$ da população economicamente ativa (PEA) no Brasil e os negros (de ambos os sexos), 46,4\%. As mulheres negras, por sua vez correspondem a 14 milhões de pessoas (18\% do PEA), revelando uma dupla discriminação de gênero e raça, em todos os indicadores: educação, mercado de trabalho, renda e pobreza, desenvolvimento humano, sobrevivência e mortalidade, e acesso a alguns bens e serviços.

Os dados do PEA apontam a dimensão da questão de gênero e raça nas formas precárias de ocupação. A porcentagem de mulheres brancas ocupadas no serviço doméstico com remuneração, é de $18 \%$ uma das mais altas entre países latino-americanos, enquanto $o$ percentual de negras é de $23,3 \%$. As mulheres brancas que se ocupam neste tipo de serviço sem remuneração é de $15 \%$ e o das negras é $17,5 \%$. Assim, as trabalhadoras domésticas de raça branca perfazem um total de $33 \%$ e o das negras $40,8 \%$ ( FARRANHA, EGG e ABRAMO , 2006 )

Mulheres no Brasil, que trabalham fora de suas casas e que, em geral, têm obrigações familiares, como cuidar de crianças pequenas, por exemplo, podem ter uma ajudante ou uma empregada doméstica, como são denominadas juridicamente, à disposição delas. Isso acontece especialmente na classe média e classe média alta. E assim, o ciclo de trabalho doméstico invisível se repete, embora, com uma remuneração, mas ainda sem visibilidade e não aparecem nas estatísticas sobre a força de trabalho. $\mathrm{O}$ crescimento do trabalho remunerado para as mulheres, apontada como uma das consequências do crescimento globalizado é suportada neste caso por dois grupos de mulheres. Nos setores mais pobres do país, onde não há demanda suficiente para os serviços domésticos informais ou outras ofertas de empregos, a prostituição de meninas e adolescentes vem crescendo e é frequentemente mencionado nos relatos da mídia local (D'AVILA NETO e NAZARÉ, 2005).

Os dados contidos em duas coletâneas - $O$ Atlas Racial Brasileiro (2004), uma realização do Programa das Nações Unidas para o Desenvolvimento (PNUD), Centro de Desenvolvimento e Planejamento Regional (Cedeplar) da Universidade Federal de Minas Gerais, e o Radar Social (2005), do Instituto de Pesquisa Econômica (IPEA) - mostram a extensão das desigualdades entre pessoas brancas e negras, tanto homens quanto mulheres.

Mello (2005) desenvolveu uma pesquisa partindo de uma resenha bibliográfica sobre pobreza na literatura socioeconômica brasileira, com um enfoque de gênero a partir dos micro dados da Pesquisa Nacional de Amostras de Domicílios (PNAD), do Instituto Brasileiro de Geografia e Estatística (IBGE) para o ano de 2001. Este trabalho tinha como hipótese que fatores de gênero incidem com maior peso na vida das mulheres, tornando-as mais vulneráveis à pobreza. A conclusão desta pesquisa, foi de que apesar do progresso na redução das desigualdades de gênero, ainda permanecem substanciais diferenças entre os sexos, agravadas pela questão racial, fazendo com que a pobreza brasileira tenha um rosto feminino negro. Os dados estatísticos mostram a situação desfavorável de mulheres afro-descendentes e evidenciam que o mito da democracia racial é uma outra dimensão do 
racismo criando uma ilusão da harmonia racial, nomeada por Carneiro (2006) como conspiração silenciosa.

\section{Entendendo a Desigualdade de Gênero e Raça}

Para uma melhor compreensão dessas desigualdades de gênero e raça, devemos buscar num plano histórico os antecedentes que remontam à época da colonização sobre o tráfico de escravos e da diáspora negra. $\mathrm{O}$ fenômeno migratório, seja voluntário ou forçado, constitui-se hoje num tema de considerável importância dentro do contexto global.

A globalização, embora tenha se acelerado nas duas últimas décadas, pode ser indicada desde o século XV, época das grandes navegações. Em sua pretensão à homogeneização cultural, provoca efeitos diferenciadores que produzem formações subalternas e não suprimem a diferença, ao mesmo tempo em que afirma e recria identidades. Este processo associado à aceleração do fluxo migratório leva às grandes desigualdades (IANNI, 1996; WOODWARD, 2006; HALL, 2006; BUTLER e SPIVAK, 2007).

Entre os séculos XVI e XIX, foram importados da África cerca de 4 milhões de escravos africanos, oriundos de diversas culturas que aqui foram dispersos por todo o território brasileiro. Chegando ao Brasil, um dos critérios de venda dos negros era a separação de etnias para evitar rebeliões. E coube a esses negros uma grande façanha cultural, que consistia no aprendizado de uma nova língua, o português, que lhes permitia a comunicação com os senhores e com outros negros, de diferentes etnias e linguagens (RIBEIRO, 1995). Mas essa 'integração' forçada trouxe também a desafricanização, como apontava Darcy Ribeiro (1995).

O colonizador mantinha sua representação eurocêntrica e hierarquizada: o Brasil seria povoado por raças inferiores: negro, índio e seus descendentes. Tzevan Todorov (1993) ilustra bem essa ideia quando comenta a atitude de Colombo frente aos nativos, durante a descoberta da América, argumentando que a diferença é sempre traduzida em termos da dicotomia superioridade/inferioridade, sendo os índios sempre inferiores. Para o autor, "esta experiência de alteridade se baseia no egocentrismo, na identificação de seus próprios valores com os valores em geral, de seu eu com o universo; na condição que o mundo é um" (TODOROV, 1993, p.41). Essas teorias implicam na dicotomia natural/cultural. O europeu colonizador teria assim a missão de educar, civilizar e branquear os negros colonizados para que um dia talvez eles se tornassem humanos.

Como relata Fritz Fanon (1952), considerado um dos inspiradores dos chamados estudos pós-coloniais, em sua obra Peau noire, masques blancs, a negação das culturas ditas inferiores é o que os primitiviza. Os ritos de passagem das sociedades africanas eram encaradas pelos colonizadores franceses como magia negra, orgia e erotismo animal.

A analogia entre raça e sexo ocupou um lugar estratégico na teoria científica do século XIX e XX, de modo que o cientista podia usar a diferença racial para explicar a diferença de gênero e vice-versa. Como argumenta Miskolci (2007):

A constituição de raça não se deu a partir de entidades naturais preexistentes, mas foi resultado do acesso desigual ao poder que criou relações discriminatórias por parte do grupo hegemônico. A designação do outro como diferente e inferior utilizou vários marcadores ao mesmo tempo, assim, por exemplo, às raças inferiorizadas atribuiu-se uma proximidade de gênero socialmente menos valorizado, o feminino (MISKOLCI, 2007, p. 17).

Esta ideologia justifica a exploração e a dominação dos afro-descendentes quando então são produzidos e reproduzidos estereótipos 'inferiorizantes', tais como: preguiça, indolência, violência e 'hipersexualidade' como apontados por Hall (2006). São pontos de vista essencialistas que estruturam a identidade e a diferença em termos binários, que caracterizam o 'Outro' como inferior, seja por heranças culturais ou biológicas, quando os excluídos e incluídos são determinados pelo grupo hegemônico: o homem branco.

Gilberto Freyre, em sua obra Casa Grande $e$ Senzala, publicada em 1933, aponta o sadismo dos senhores de escravos ressaltando também a situação da mulher negra escrava. Foram associadas à luxúria e consideradas 'responsáveis' pela depravação da sociedade colonial luso-brasileira, uma vez que iniciavam precocemente rapazes brancos na vida sexual. O autor narra no artigo: Luxúria - Legado da Escravidão publicado na 'Antologia do Negro Brasileiro' de Edson Carneiro em 1950, que trata da árdua trajetória dos negros no Brasil, a crença que por muito tempo predominou: para o sifilítico não havia melhor remédio do que uma 'negrinha' virgem.

Cabe aqui, explicar alguns conceitos dentro do quadro teórico proposto. Stuart Hall (2006) ressalta a importância de diferenciar multicultural do multiculturalismo. A sociedade multicultural é aquela em que diferentes culturas estão interconectadas 
socialmente, mas preservam características de uma identidade 'original'. Já o multiculturalismo seria a forma de administrar sociedades multiculturais e está ligado às demandas de reconhecimento. Dessa forma, o multiculturalismo deve ser entendido como um projeto político e epistemológico em relação ao eurocentrismo, como o define Shoat (COSTA, 2001), teórica e feminista pós-colonial. Associado a essa linguagem, o multiculturalismo pode ser entendido como uma compensação aos efeitos danosos da dominação, cuja maior evidencia para Cornell e Murphy (2002) é o racismo.

Smith (2006), explica que o termo hibridismo era pejorativo em sua origem, utilizado para afirmar a supremacia europeia em relação a outras raças e culturas, perpetuando assim a exclusão de grupos minoritários, Dentro do quadro teórico pós-colonial, o hibridismo é encarado como uma forma de minar o discurso das culturas ditas superiores, evidenciando a apropriação e a reavaliação de culturas minoritárias, afirmando novas identidades e a busca pelo reconhecimento.

Paul Gilroy (1993), outro teórico dos estudos culturais, lembra que o termo diáspora foi importado do pensamento judeu para o vocabulário de estudos negros pelas 'comunalidades' dos temas que dizem respeito aos dois povos, ou seja, dispersão, exílio e escravidão, ressaltando a importância do conceito em relação à afirmação da identidade étnica e da diferença.

Smith (2006) coloca que a diáspora é um sentimento ambivalente, por um lado ligado ao território de origem e por outro ao exílio. Dessa forma, as práticas culturais não são ligadas a um lugar, são práticas desterritorializadas, e é justamente essa mobilidade e fluidez é que são importantes hoje, porque se tornam um ato político nas quais novas identidades hibridas vão se formando e buscando reconhecimento.

Considerando o Brasil como uma sociedade na qual predomina a desigualdade econômica, a dificuldade de acesso aos sistemas de saúde pública ou privadas, à educação, ao trabalho digno, lazer e moradia, sendo mulheres afrodescendentes as mais desfavorecidas, podemos levantar a questão do reconhecimento da diferença cultural e a desigualdade social, sob a perspectiva teórica de Nancy Fraser (1997), que preconiza o reconhecimento ao lado da redistribuição. A autora teoriza a busca de reconhecimento considerando as intersecções entre gênero e raça, ou seja, levando em conta suas transversalidades. Ela expõe as relações entre (des)vantagem econômica e (des)respeito cultural que, seria a única forma de combater as injustiças sociais. Assim, no enfoque dos eixos culturais e socioeconômicos da injustiça, de forma paradigmática, gênero e raça irão questionar em que circunstâncias uma política de reconhecimento pode apoiar uma política de redistribuição.

\section{A Narração Pós-Colonial: Reconfigurando a 'Lógica da Dominação'}

Inicialmente, queremos trabalhar com uma questão, frequentemente, ignorada no discurso pós-colonial do Brasil, e que retomamos de Boaventura Santos, professor da Universidade de Coimbra. A proposta de Santos é que para examinar o colonial na sociedade brasileira, devemos examinar o colonial gerado por Portugal, país que nos colonizou, diferentemente, de países de colonização hispânica da América Latina, ou mesmo inglesa, francesa ou outra predominante em outras partes do mundo.

Em seu ensaio sobre Próspero e Caliban, intitulado Between Prospero and Caliban: Colonialism, Postcolonialism, and Inter-identity, publicado em 2002, utilizando a metáfora do texto de Shakespeare, explica que, embora, Portugal tenha sido um colonizador, manteve-se como colonizado, em relação ao resto da Europa, criando um jogo de múltiplos espelhos, onde ora era Prospero, ora Caliban, ora eurocêntrico, ora selvagem.

Santos tem como hipótese de que no Brasil teríamos sofrido a ambivalência de uma identidade de um duplo outro, de nossos colonizadores diretos (Portugal) e indiretos (aqueles dos quais Portugal se mantinha como colonizado, como era caso da Inglaterra). Ele lembra que no caso do Brasil, nossa independência deu surgimento a formas políticas altamente conservadoras e oligárquicas, sendo o único país a permanecer monarquia no continente latinoamericano, antes de se tornar uma República.

As identidades dominantes e subalternas que derivam daí indicam diferentes formas e jogos de poder que podemos detectar em nossa constituição colonial. No Brasil colonial, havia um intrincado complexo de relações baseadas na autoridade e dominação envolvendo o mundo senhorial. Poderíamos rotular as variações na existência do poder como o poder doméstico, poder senhorial, e poder aristocrático (FERNANDES, 1976). Encontramos, nesse mundo colonial, as origens do nosso sistema patriarcal, onde a autoridade do patriarca era incontestável, no domínio da família, mulheres, filhos e escravos. A mulher negra era destinada a prestação de serviços (incluindo favores sexuais). Segundo D'Ávila e Pires (2000), nesse mundo colonial de autoridade patriarcal se engendraram, ao mesmo tempo, a exaltação à mulher virgem refletida na 
devoção à Virgem Maria associada ao poder mítico ou mágico para pessoas de cor e, sobretudo, as suas mulheres que são conhecidas como mulatas. Isso continua a ser destaque hoje no setor do turismo cultural.

Os aspectos patricêntricos revelaram o poder político, mas para as mulheres o poder está relacionado ao poder mítico ou mágico, ou seja, pertence à esfera imaginária. É interessante acompanhar a elaboração das hipóteses identitárias de Santos, pois elas refletem inúmeros autores, inclusive brasileiros, como é o caso de Oswald de Andrade ${ }^{1}$, falando da antropofagia nas representações coloniais. A representação do Brasil e por extensão das Américas, integrando o imaginário eurocêntrico dos viajantes no período colonial, vai oscilar entre a utopia idílica da terra prometida e o canibalismo selvagem. A negação total do outro se faz pela sua produção ativa e, ao mesmo tempo, pelo seu desejo, mas a ambivalência do jogo alternado dos portugueses entre Próspero e Caliban indica uma produção tardia da negação e confrontação do outro subalterno.

Todos esses aspectos são importantes para entendermos a miscigenação racial que ocorreu na colonização portuguesa, no caso, no Brasil. Embora ela, associada ao ideal universalista da constituição da nação brasileira, amplamente influenciado pelas ideias de um positivismo político, tenha permitido o mito da 'democratização racial', entre nós, a miscigenação, do ponto de vista colonial, não é a ausência de racismo, mas um tipo de racismo.

Se tentarmos aplicar às mulheres brasileiras, a partir da metáfora de Próspero e Caliban, nossa primeira representação é de que a mulher representaria Caliban, enquanto o homem, o colonizador, Próspero.

Isso era evidente no Brasil Colônia, mas de modo diferenciado, se mulheres brancas ou negras. A negra deveria prestar serviços aos senhores brancos, onde estavam incluídos os serviços sexuais com seu senhor branco. Inúmeros outros escravos nasciam das relações sexuais do homem branco colonizador com suas escravas. Mas, os homens negros escravos, poderiam ser punidos com a morte caso se unissem às mulheres brancas. Tal fato era fora de questão, num Brasil escravocrata.

A mulher branca, obediente ao pai, só deveria mudar de senhor ou obediência, quando casada e, se permanecesse solteira, sua 'vocação' seria a de uma religiosa, obediente a Deus e a Cristo. Para os conventos, aliás, foram enviadas as jovens celibatárias, mas também as que transgrediam as 'regras' e engravidavam, fora do casamento, por exemplo. Eram denominadas 'mulheres desonradas', porque haviam 'perdido a honra'.
A mulher Caliban não era somente a negra e a mulata, mas também a índia e a própria branca, em relação ao seu 'senhor'. As mulheres não brancas poderiam ser Calibans em relação às brancas, que poderiam ser o Próspero daquelas e assim numa multiplicidade de jogos de espelhos, onde a classe social desempenhava um papel importante, conjugando-se à raça e gênero. Vemos aqui o que Stuart Hall (2006) chama de dispersão do poder, numa forma gramsciana, referindo-se às diferentes formas de dominação, que não podem ser 'essencializadas', e que estão na base dessas relações.

\section{Traduzindo a Diáspora Negra: Descolonizando o Corpo e a Memória}

O papel dos pesquisadores poderia ser o da tradução. Tradução cultural, ou melhor dizendo, transcultural, assumindo a impossibilidade do universalismo e recriando fronteiras, desfazendo suas arbitrariedades. Traduzir a cultura dos subalternos tem sido objeto de inúmeras discussões na literatura póscolonial e de grande parte das críticas feministas contemporâneas. Tornou-se um clássico o discutido texto da indiana Spivak (1999), radicada nos Estados Unidos: Can the subaltern speak? O intelectual póscolonial de Santos, Hall, Spivak - ou o intelectual orgânico de Grasmsci, ou o intelectual mulato de Darcy Ribeiro - é fundamental na expressão dessa crítica política. Examinar a diáspora negra significa examinar a questão sob diferentes ângulos caracterizando como Stuart Hall supõe new ethnicities (1989; 1996).

Referindo-se a Hall, Santos explica:

Ele quer dizer que os grupos diaspóricos que contestam a rigidez das representações impostas a eles no nome de suas experiências sociais diferentes e posições subjetivas (por exemplo, 'negro'), e procuram por formas alternativas de organização para aqueles patrocinados pela sociedade dominante por causa da sua própria legitimação, ao invés de resolver os verdadeiros problemas dos imigrantes (SANTOS, 2002, p. 15).

É evidente que é impossível tratar da questão sem levarmos em consideração a interseção sexo, raça e classe para evidenciarmos a 'epistemologia da dominação', como propõem feministas como Elsa Dorlin (2009) na França ou Jurema Werneck, no Brasil, discutindo o feminismo do sul. 
O enunciado 'eurocêntrico' que definiu e ainda define as 'mulheres do sul' - por oposição ao feminismo branco ocidental - costuma ser o obstáculo e o motivo de denúncia por parte do feminismo que se pretende não eurocêntrico, o Black Feminism, o feminismo das Chicanas, New Mestizas, dos Borderlands, etc.

Há uma convergência entre diversos autores que indica a necessidade de se traduzir através dos corpos e experiências, a enunciação dos grupos minoritários ou subalternos. Não se trata de trocar enunciados verbais por gestuais, é mais do que isso. Trata-se de buscar novas formas de enunciados, mais fluidos, mais híbridos, mais próximos das utopias emancipatórias.

Cecilia W. Francis (2002), num capítulo sob o título Enunciação, Discursos e Estratégias Identitárias na Obra de Leila Sebbar, chama atenção para a 'cenografia de sujeitos de enunciado culturalmente minoritário'. Tais sujeitos, diz ela, analisando a obra da escritora algeriana Leila Sebbar, que se desloca na adolescência para a França, "testemunham uma carga importante pela dimensão (...) da linguagem" (FRANCIS, 2002, p. 132-133). É essa alteridade que Francis se propõe examinar na obra pós-colonial:

A alteridade tem ressonâncias, enquanto obra de ruptura em busca de uma expressão suscetível de traduzir experiências de vida radicalmente diferentes de uma tradição europeia (...), um retorno a formas primitivas da sensibilidade e da imaginação. O papel do sujeito 'patemizado' coloca simultaneamente em relevo a economia cognitiva do corpo testemunho, a disposição dos saberes no interior do recito (...) que não é assumida da mesma maneira que por um europeu falando do mundo colonial como por um autóctone, um colonizado, um imigrado, ou um sujeito feminino. (FRANCIS, 2002, p.133, p. 136)

Como indica Rose Braidotti (2000), o ponto de partida do projeto da diferença sexual mantém, primeiramente, sua vontade política de afirmar a especificidade da experiência vivida, corporalmente feminina, rechaçando a diferença sexual descorporificada em um sujeito supostamente pósmoderno e 'antiessencialista'. Francis (2002, p.133) assinala que "essas estratégias identitárias irritam o recito pós-moderno, ocupado pelo desmantelamento do sujeito positivista e falocêntrico". Braidotti (2000) comenta que, segundo Teresa de Lauretis, devemos reconhecer que há uma diferença entre a representação da mulher (a mulher como imago cultural) e a mulher como experiência (as mulheres enquanto agentes de mudança). Em sua proposta que chama de posição feminista nômade, Braidotti reconhece as diferentes formas de representar a mulher, argumentando que isso é necessário para evitar caracterizações divisórias na prática feminista. Assim, a identidade mulher não pode ser definida como o não-homem, ou como uma essência. A nova figuração do sujeito feminino, sustenta Braidotti (2000, p. 194), é um projeto transdisciplinar, argumentando que "é preciso um intercâmbio mais efetivo entre teóricas e artistas, acadêmicas e mentes criativas". Para ela isso implica:

O corpo não pode captar-se ou representarse plenamente: excede à representação. (...) Para mim, a identidade é um jogo de aspectos múltiplos, fraturados de si mesmo; é relacional, porque requer o vínculo com o outro (BRAIDOTTI, 2000, p. 194).

Parece-nos que, embora mantendo a disposição de uma redefinição de representação do sujeito mulher, essa disposição se volta para uma corporificação, o que é, sem dúvida, um fator de complicação. O corpo, do mesmo modo que a linguagem, também é um lugar de expressão do poder.

É importante notar que a análise de Cecília Francis (2002) para captar a linguagem do pós-colonial, utiliza o recurso ao visual, mostrando como o personagem Sherazade vai configurando sua $a g e n c y^{2}$ em relação à sua própria identidade narrativa.

Este programa de aprendizagem aleatória subtende nela (a personagem) a emergência de competências de script, o que supõe uma transformação do sujeito, sobretudo no que concerne às suas modalidades de ver e compreender. Assiste-se, efetivamente, a uma liberação gradual - sexual e cultural do sujeito feminino, mestiçado por meio de um percurso visual, implicando a inversão na ordem das hierarquias do sujeito que é olhado e o que olha (FRANCIS, 2002, p.145).

Observe-se que o ocorreu na sociedade brasileira, onde a 'modelização' de virgem, pureza e honra associados às mulheres brancas - ou todas as que são associadas à acepção de brancura - em seu protótipo da Virgem Santa, traço de uma colonização europeia de origem católica, e os da mulata, repreendida pelos seus 'feitiços, dengues e quindins', na expressão de Nina Rodrigues (1938) e glorificada pelo 'sexo que é mais sexo' (FREYRE, 1933; 1986). Ambas, são como duas 
faces da mesma moeda: a primeira tem seus poderes pelo sexo não tocado e a segunda, exatamente pelo exercício do sexo, que é 'mais sexo', como também se expressou Freyre (1933). Esses poderes, entretanto, não são da ordem do político, permanecem na esfera do imaginário, como uma espécie de depositário identitário que confina a mulher em substância corporal, disciplinada pelo uso que lhe é imposto da sexualidade, naturalizando tarefas e papéis que decorrem de uma ou outra acepção dessa modelização.

Há sem dúvida, uma importante ligação aí com a questão do reconhecimento, como encontramos em trabalhos relativamente recentes de Axel Honneth (2006) sobre questões da gramática moral do reconhecimento. Sua preocupação é com a corporeidade ou materialização do reconhecimento, em que cada forma de reconhecimento social tem, sem dúvida, necessidade de um substituto simbólico para as formas corporais de reconhecimento. Nesse sentido o reconhecimento social é alguma coisa que tem igualmente uma presença física no nosso quotidiano ${ }^{3}$.

A concepção de reconhecimento assim explicitada pode ser um passo importante metodológico para uma pesquisa mais focada no que é chamada a 'fronteira', menos presa a suas restrições logocêntricas, de caráter mais pragmático face ao quotidiano, mais sensível à 'sociologia dos silêncios' e 'sociologias das emergências', na expressão de Santos (2006).

\section{Reconhecimento: Remediar ou Transformar?}

Retomando a questão do reconhecimento e da redistribuição, que lhe é concomitante, do ponto de vista cultural e econômico, evidencia-se em nosso relato pós-colonial que o racismo, como o gênero, é um grupo misto. E isso é flagrante na herança secular de nossa colonização europeia Como propõe Fraser (1997) a justiça social é conceituada com dois parâmetros: a primeira socioeconômica e a segunda cultural ou simbólica. As questões estão imbricadas tanto na estrutura socioeconômica da sociedade, como nos sistemas sociais de representação. O remédio para desigualdades econômicas seria a 'redistribuição' com reestruturações de ordem política e econômica; já para as injustiças culturais a solução seria o 'reconhecimento', valorizando a especificidade de um grupo. Neste trabalho, que evidencia as desigualdades de gênero e raça, deve-se considerar que as duas categorias necessitam de redistribuição e reconhecimento.

Gênero sofre dois tipos de injustiça, uma de dimensão político-econômica pela divisão do trabalho 'reprodutivo', 'produtivo' e doméstico, onde o 'sexismo' cultural representa de forma desvalorizada as atividades ditas 'femininas' e o 'androcentrismo' que as inferiorizam.

O dilema colocado é que a necessidade de reconhecimento e redistribuição aponta para uma contradição. Não se poderia eliminar concomitantemente a diferença de gênero, valorizando sua especificidade. $\mathrm{O}$ mesmo tipo de lógica se aplica à 'raça'. Se as afro-descendentes são as mais desfavorecidas nos indicadores socioeconômicos, legado do colonialismo e da escravidão sofre, portanto uma injustiça, mas também são vítimas do racismo cultural com todas as suas estereotipias provenientes do eurocentrismo, o que demandaria reconhecimento. Desta forma, volta-se ao mesmo dilema de gênero, como seria possível eliminar a diferença de 'raça', valorizando a especificidade do grupo? Ambos os grupos, cada um com sua especificidade englobam demandas tanto nas dimensões político-econômicas como nas cultural valorativas, logo necessitam de redistribuição e reconhecimento. Fraser vai propor para as questões os remédios 'afirmativos' e 'transformadores'. Para gênero, propõe como estratégia transitória que implica na combinação entre redistribuições transformativas, que consistiria em alguma forma de democracia social feminista, viabilizada a partir de uma igualdade social. Para o dilema 'raça', a autora propõe a mesma solução, alguma forma de antirracismo socialista democrático para reparar a injustiça social na economia e reconhecimento transformativo para reparar injustiças sociais na cultura, visando à desestabilização de dicotomias raciais.

Assim, tanto para gênero como para 'raça', aqui, tratados separadamente a solução mais adequada para solucionar o dilema redistribuição/reconhecimento seria o socialismo na economia e a desconstrução na cultura.

No que se refere às mulheres afro-descendentes, há uma intersecção de inúmeras possibilidades de subordinação e formas de injustiça que se perpassam mutuamente. Há que se pensar formas cruzadas do dilema redistribuição/reconhecimento. Isso implica em aceitar parcial e provisoriamente os remédios paliativos, como tendo sido o caso das políticas afirmativas no Brasil e, especialmente, em não cometer o mesmo erro que o pós-colonialismo critíca, que é o de essencializar as posições de colonizados e colonizadores, buscando entender raízes sóciohistóricas não como 'purezas intocáveis', mas como elementos indispensáveis à compreensão de hábitos quotidianos. Tal é o caso dos alimentos na cozinha brasileira, que além de elementos europeus e indígenas, é um espaço de hibridização com os 
elementos africanos, sendo fortemente ancorada nas suas tradições profanas e/ou religiosas, como é o caso do Candomblé. É importante notar que, nesse culto religioso afro-descendente, as mulheres são figuras de preponderância hierárquica sobre toda comunidade de fiéis, sendo suas mais importantes sacerdotisas, denominadas 'mães de santo'.

Uma mais conveniente tradução das afrodescendentes poderia estar nas metodologias multimodais, onde aos testemunhos e entrevistas podemos acrescentar os registros visuais, suas reinterpretações conjugadas, deslocando os discursos das suas posições de dominação e subalternidade tradicionais, numa tentativa de realizar uma versão transcultural dessa tradução, que academicamente vai se revelar tributária de uma 'transdisciplinaridade', num esforço continuado de ler suas fontes na trajetória 'histórica-geográfica-psicossociológica' e política que implicam suas disciplinas, no quotidiano e nos movimentos sociais, nos hábitos assimilados e na sua subversão híbrida. No 'real', corporificado, materializado e no imaginário das relações intersociais.

Fronteiras excluem, definem e subjugam o outro como diferente, estranho, perigoso, mantendo-o à parte, mas também podem recriar, subverter, traduzir novas subjetividades, Podemos supor que a lógica do opressor/colonizador também se integra à identidade do oprimido/colonizado, e, provavelmente no sentido inverso, essas narrativas de mulheres de grupos minoritários têm, de um modo ou de outro, múltiplos rostos que se narram por suas vozes, corpos e colonizadas memórias.

1 Em 1928, o poeta brasileiro Oswald de Andrade publicou seu Manifesto Antropófago.

2 O termo agency foi proposto para demarcar a capacidade do sujeito feminino de "agir de forma autônoma, de modificar a construção social de sua própria subjetividade, de seu lugar e de sua autorepresentação no interior de um universo social" (NEUMAN, 1993 apud FRANCIS, 2002, p. 145).

3 Tradução dos autores.

\section{Referências}

ANDRADE, Oswald. A utopia Antropofágica. São Paulo: Editora Globo, 1990 [1928].

BRAIDOTTI, Rosi. Sujeitos nômades. Buenos Aires: Paidós, 2000.
BUTLER, Judith; SPIVAK, Gayatri Chakravorty. L'État global. Paris: Éditions Payot \& Rivages, 2007.

CARNEIRO, Suelaine. Desigualdades Raciais: Fontes de Conflito e Violência Social. São Paulo: Instituto Ethos, 2006.

CORNELL, Drucilla; MURPHY, Sara. Anti-racism, multiculturalism and the ethics of identification. Philosophy \& Social Criticism. vol. 28, nº 4, p. 419 449, 2002.

COSTA, Claudia de Lima. Feminismo Fora do Centro: Entrevista com Ella Shohat. Revista Estudos Feministas, vol. 9, nº 1, p. $147-163,2001$.

D’ÁVILA NETO, Maria. Inácia.; PIRES, Cintia. "Empowerment or power-sharing? Considerations based on gender equity research in Brazil". In: KEARNEY, Mary. Louise. (org.). Women, Power and the Academy: from rhetoric to reality. Nova York: Berghahn Books, 2000.

D’AVILA NETO, Maria. Inácia.; NAZARETH, Juliana. "Globalization and Women's Employment, Peace Review". A journal of social justice, vol. 17, n. 2 - 3, p. 215 - 220, 2005.

DORLIN, Elsa (org). Sexe, Race, Classe - pour une epistemologie de la domination. Paris: PUF, 2009.

FRANCIS, Cécilia. Wiktorowicz. "Enonciation, discours et stratégies Identitaires. Une phénoménologie de l'alterité dans l'œuvre de Leila Sebbar". In: OUELLET, Pierre. (et al.) Identités Narratives, Mémoire et Perception. Quebec: Presses Universitaires de Laval, 2002.

FANON, Frantz. Peau noire, masques blancs. Paris: Du Seuil, 1952.

FARRANHA, Ana Claudia; EGG, Rafaela (org). Igualdade Racial: principais resultados - Projeto Desenvolvimento de uma Política Nacional para Eliminar a Discriminação no Emprego e na Ocupação e Promover a Igualdade Racial no Brasil. Brasília: Secretaria Regional-OIT, 2006.

FERNANDES, Florestan. A Sociedade Escravista do Brasil (The slavish society of Brazil) paper presented in the Academy of sciences. Nova York, 1976.

FRASER, Nancy. "From Redestribution to Recognition? Dilemmas os Justice in a 
'Postsocialist"'. Justice Interruptus. Nova York: Routledge, 1997.

FREYRE, Gilberto. Masters and Slaves. Berkeley: University of California Press, 1986 [1933].

$$
\text { [1933]. }
$$

Maîtres et Esclaves. Paris: Gallimard, 1952

GILROY, Paul. The Black Atlantic: Modernity and Double Consciousness. Nova York: Verso, 1993.

HALL, Stuart. "New Ethnicities". In: MORLEY, D.; KUAN-HSING, C. (org). Stuart Hall: Critical Dialogues in Cultural Studies. Londres/Nova York: Routledge, p. 441-449, 1996 [1989].

HALL, Stuart. "Pensando a Diáspora: Reflexões Sobre a Terra no Exterior". In: SOVIK, Liv. (Org). Da diáspora - identidades e mediações culturais. Belo Horizonte: Editora UFMG, 2006.

HONNETH, Axel. La société du Mépris-Vers une Nouvelle Théorie Critique. Paris: Ed La Découverte, 2006.

IANNI, Otavio. A era da globalismo. $2^{\mathrm{a}}$ ed. Rio de Janeiro: Civilização Brasileira, 1996.

IBGE (Instituto Brasileiro de Geografia e Estatística). Disponível em: http://www.ibge.gov.br/. Acesso em: 10 de fevereiro de 2009.

IPEA. Radar social. 2005. Disponível em: http://www.ipea.gov.br/Destaques/livroradar.htm. Acesso em: 10 de setembro de 2008.

MELLO, Hildete Pereira de. A pobreza e as políticas de gênero no Brasil. Santiago de Chile: Cepal, 2005.

MISKOLCI, Richard. Teoria Queer e a Questão das Diferenças: ou uma analítica da normalização. Texto escrito a partir de palestra proferida pelo autor no $16^{\circ}$ COLE - Congresso Brasileiro de Leitura. UNICAMP - 2007a. (Mimeo).

PNUD-CEDEPLAR. Atlas racial brasileiro. Disponível em:

http://www.pnud.org.br/publicacoes/atlas_racial/in dex.php. Acesso em: 10 de setembro de 2008 [2004].

RIBEIRO, Darcy. O Povo Brasileiro-Formação e Sentido do Brasil. São Paulo: Companhia das Letras, 1995.
RODRIGUES; Nina. Raças Humanas e Responsabilidade Penal no Brasil. São Paulo: Companhia Editora Nacional, 1938.

SANTOS, Boaventura de Sousa. Between Prospero and Caliban: Postcolonialism, and Inter-identity. LusoBrazilian Review, vol. 39; n², p. 9-43, 2002.

A Gramática do Tempo para uma nova cultura política. São Paulo: Ed Cortez, 2006.

SMITH, Andrew. Migrance, Hybridité ét Études Littéraires Postcoloniales. In: LAZARUS, Neil. (Org.). Penser le Postcolonial. Paris: Amsterdam, 2006.

SPIVAK, Gayatri. A Critique of Postcolonial Reason: toward a History of the vanishing. Present Cambridge, M.A: Harvard University Press, 1999.

TODOROV, Tzvetan. A conquista da América: a questão do outro. São Paulo: Martins Fontes, 1993.

WERNECK, Jurema. Of Ialodês and Feminists: Reflections on Black Women's Political Action in Latin America and the Caribbean. Cultural Dynamics, vol. 19, nº 1, p. 99 - 113, 2007.

WOODWARD, Kathryn. Identidade e diferença: uma introdução teórica e conceitual. In: SILVA, Tomaz Tadeu da. (Org.). Identidade e Diferença: a perspectiva dos estudos culturais. $6^{\mathrm{a}}$ ed. Petrópolis: Vozes, 2006.

Recebido em 29 de setembro de 2010. Aceito em 07 de março de 2011. 